\title{
Chinese as a Cultural Capital: The Case Study of Chinese Heritage Language Learners
}

\author{
Budi Kurniawan ${ }^{1}$, Setefanus Suprajitno ${ }^{2}$ \\ Petra Christian University, INDONESIA \\ e-mails: ${ }^{1}$ budi.kurniawan@ @etra.ac.id, ${ }^{2}$ steph@petra.ac.id
}

\begin{abstract}
Chinese language education in Indonesia is closely related to the social, political, and cultural dimensions of the country. The change of power in the country in 1998 affected the development of the Chinese language. Since the ban imposed on Chinese language and culture since 1965 was lifted, there have been an increasing number of Chinese language schools. Under the theoretical frameworks of Gardner's motivational orientations and Bourdieu's cultural capital, this study explored varied motivations of Chinese Indonesians to learn Chinese, and how their perception of China influenced their efforts in learning the language. Data were obtained through focus group discussions and interviews. The findings showed that integrative and instrumental orientations were found among participants, but due to the learners' social milieu, instrumentality of Chinese dominated their orientations. The instrumentality of Chinese and the positive perception of China worked together to make the Chinese language as a cultural capital for these CHL learners.
\end{abstract}

Keywords: Chinese heritage language; Chinese Indonesians; cultural capital; instrumentality; integrativeness; learning motivations.

\section{INTRODUCTION}

The linguistic landscape of Chinese language learning in Indonesia has been changing throughout its history. It underwent a period of serious decline during the 32year reign of Suharto's New Order (1966-1998), when the state banned Chinese culture. Chinese Indonesians were practically stripped of their heritage language, and those who were born and raised during this time and their subsequent counterparts do not speak the language. After the fall of Suharto in 1998, the state has allowed Chinese Indonesians to express their culture. Since then on, there has been a revival of Chinese culture. Chinese language education has received a huge interest not only from the ethnic Chinese, but also from other ethnic groups. Many language centers and Chinese departments in universities have been founded. The interest of learning Chinese among Indonesians can be seen in the number of the people taking Hanyu Shuiping Kaoshi (HSK), an international standardized test of Chinese proficiency that assesses non-native Chinese language speakers' ability in using the language in their daily and professional lives. The number of HSK testtakers in Indonesia increases every year. In October 2017, there were 8,397 test-takers. This figure shows a $4.8 \%$ increase from the number of test-takers in October 2016 (Chen, 2017).
It was Chinese organizations, whose members were mostly Chinese Indonesians receiving Chinese education, who initiated the establishment Chinese language institutions. They thought that it was their duty to pass down the Chinese language and culture to the Chinese descendants who were born and raised during the New Order era, who did not know about their cultural heritage and had lost command of the Chinese language. They saw "this duty" as a way to bring the latter back to the essential "root" of Chinese cultural values (Hoon, 2011; Chen, 2005). Some of the latter may agree with this idea. They learnt Chinese because of their interest in their cultural heritage. However, there were those who learnt Chinese mainly for economic prospects (Hoon, 2007), not for identifying themselves as Chinese, which was at most just symbolic, rather than actual identity marker (Tong, 2010, p. 132).

Their motivation for learning Chinese for economic prospect cannot be separated from the China factor. Due to the rise of China as a global power, Chinese has become a crucial language to learn across the globe. The impact of China's economic growth has created a new atmosphere in learning Chinese, which is also spurred by China's effort to cultivate its soft power by promoting Chinese language and culture. This is often seen as a part of China's public 
diplomacy program to strengthen its discursive power (Zhao, 2016, p. 559), on par with its economic muscle. In line with China's increasing political and economic power in the world, the number of Chinese language learners, including those in Indonesia, is also increasing. They expect that Chinese can provide them economic opportunities for their future. That is why many Indonesians, regardless of their ethnicity, see the importance of learning Chinese. They learn it because they want "to capitalize on the rise of China" (Shih, 2017, p. 6). The interest of Indonesian public in learning Chinese is also propelled by the policy of the Ministry of National Education in 2004, which formalized Chinese as a second foreign language subject set in curriculum and taught in public schools (Sutami, 2007; Zong \& Liu, 2007). This educational policy strengthens the position of Chinese in Indonesia and attracts people learning it.

The two opposite reasons of learning Chinese reflect the varied nature of Chinese language learning in Indonesia, especially among Chinese Indonesians. It is worth to empirically explore what motivates them to learn Chinese, their heritage language. Some previous studies on the motivations of Chinese heritage language (CHL) learners were focused on classification, relationships, and magnitude of the motivations (Wen, 1997, 2011; Yang, 2003; Zhang, 2015), but there are none that delve deeply on the sociocultural aspects of the motivations of Indonesian CHL learners. In this paper, we want to find out what makes this group of people learn Chinese. Because studies on motivations also mention that the motivations to learn languages are also influenced by the image of the community of the target language, we also want to find out how they perceive China and how their perception influences their efforts in learning Chinese.

\section{THEORETICAL FRAMEWORK}

Our study is informed by Bakhtin's idea that language is a discourse, and its usage is social (1991, p. 291). According to Bakhtin, language is "dialogic," namely, an utterance is always characterized by "addressivity" and "answerability." Speakers address their utterance to others, and at the same time their utterance anticipates an answer or a response. In a conversation, an utterance "is like a link in a chain of [utterances], "reacting to, drawing in, and transforming other [utterances]" (Bakhtin, 1986, p. 162). In the Bhaktinian perspective, language learning is seen as learners' effort to strive to use language for participating in a speech community, and the motivation to learn a language plays an important role in the learning process.
For the last few decades, a number of scholars have been studying motivation in the language learning field. One of the widely accepted theories on motivation is proposed by Gardner, known as "the socio-educational model" (Gardner, 2001, p. 4). In this model, he classifies language learners' motivation into two orientations. These orientations are traditionally known as instrumental and integrative motivation. Instrumental motivation is propelled by pragmatic reasons. Language learners have this motivation if they study the target language for the sake of utilitarian purpose, like for advancement in their career, whereas, integrative motivation is influenced by language learners' genuine interest in the target language. They have this motivation if they learn it because they want to identify themselves with its community, to the point that they wish to be accepted as a member of the cultural community of the target language. Language learners who have this motivation tend to develop a positive attitude toward the language they learn and its culture.

Gardner's socio-educational model serves as the foundation for studying the motivational role in language learning. Some scholars, such as NorrisHolt (2001) and Mandell (2002), believe that instrumental motivation is more important than integrative motivation. Norris-Holt (2001) finds that in Japanese context, it is the instrumental motivation that encourages students to learn English. Mandell (2002) finds that most students who learn postsecondary level Spanish in a U.S. city where there is a growing Spanish-speaking population have instrumental motivation. They study the language because of the institutional requirement. Other scholars, Noels (2005) and $\mathrm{Lu} \& \mathrm{Li}$ (2008) for instance, find that integrative motivation is the primary factor for the success of learning a language. In her study on students learning their heritage language, Noels (2005) found that they learn the language because they think it is a part of their identity. Lu's and Li's research (2008) resonates with Noels'. CHL learners in their research have integrative motivation. They believe that Chinese is an important aspect of their identity. Yet, there are those who finds that both integrative and instrumental motivation play a significant role (Masgoret \& Gardner, 2003). These contradictory findings necessitate further investigation on the study of motivation. For example, Hall, Cheng, and Carlson (2006) propose a usage-based view of language knowledge. In their opinion, individuals learn a language through interaction with others in activities by using cultural tools. Norton and Toohey concur with them, saying that "speakers of multiple languages are able to engage in an interaction in those languages as a result of their access to participation in 
the activities where those languages are used" (Norton \& Toohey, 2011, p. 416). These scholars, Hall, Cheng, and Carlson (2006), as well as Norton \& Toohey (2001), believe that language competence is the result of participation in performance in activities using language tools, and that individuals differ in their access to participation, according to their social and cultural positioning.

Investigation on the relationship between language and social and cultural positioning are informed by Bourdieu's notion of symbolic power (Bourdieu, 1991). For Bourdieu, language has a symbolic power because of its value. In his opinion, language has "a symbolic asset which can receive different values depending on the market on which it is offered" (Bourdieu, 1977, p. 651). He states that dominant usage is associated with dominant class, which can be in the political or economic sphere. Inspired by this idea, Heller writes that access to language is parallel to access to other resources which are also produced and "circulated in a regulated way, which allows for competition over access and typically unequal distribution" (Heller, 2008, p. 50). This perspective informs us that language use can provide a "cultural capital" to its users.

By using the economic metaphor "cultural capital," Norton coins a concept of investment in response to the inability of motivation to explain the fluctuating and often contradictory efforts of language learners (Norton \& Toohey, 2011, p. 420). Norton's concept of investment acknowledges that language learning is always situated in specific social contexts, which affect how language learners spend their efforts in learning language. When they invest their time, energy and emotion in learning a language through, for example, understanding the community of the speakers of the target language and their cultural norms, they hope their effort pays in the form of their increasing cultural capital.

Through the experiences of the participants in this study, Gardner's motivational orientations are used for examining the participants' driving force in learning Chinese. Bourdieu's term cultural capital is employed for analyzing the participants' perceived gain in their effort to learn Chinese. Both Gardner's motivational orientations and Bourdieu's cultural capital could shed some light on what makes, our participants, Chinese Indonesians living in Surabaya to learn Chinese.

\section{METHOD}

\section{Participants}

In this study, we selected participants who claim to be Chinese Indonesians. All of them live in Surabaya.
We had sixteen participants aged twenty through late twenties, all of whom are still learning Chinese in various formal and non-formal institutions. We also had two participants who were mid-forties mothers of teenagers who are also learning Chinese, and a teacher and a principal of a Chinese language school, both of whom were in their sixties.

\section{Instrument and Procedure}

We used Focus Group Discussions (FGD) and interviews to collect data. We conducted two FGDs. The participants of the first FGD were eight college students. They are sophomores and juniors. The participants of the second FGD were also eight participants, who are in their late twenties. They graduated from college one to three years ago, and are currently attending Chinese language course in language centers. Most of them work in business. We also had an interview with the principal and teacher who also serves as vice principal in a Chinese course in Surabaya, and two interviews with the mothers of students who studied Chinese in a formal setting. Questions in the interviews and FGDs covered the participants' experiences in learning Chinese, the importance of learning it, their opinions about the language, and factors influencing their learning motivation. The questions for the interviews and FGDs were semi-structured, conducted in Indonesian. The interviews lasted 30-60 minutes, while the FGDs took 90-100 minutes.

\section{FINDINGS AND DISCUSSION}

Results of the interviews and FGDs showed three themes related to the participants' efforts in learning Chinese. Those themes were family background, motivational orientations, perception on the rise of China, all of which influenced their linguistic investment.

\section{Family Background}

Participants' family backgrounds vary. At one end, some come from families in which Chinese is a foreign language, despite being ethnically Chinese.

Gia: ... none of my family members speak Chinese.

At the other end, there are those who come from a family where Chinese is spoken among family members.

Sam: My family background is Chinese-speaking. ... They [parents and their generations] speak Chinese.

In between, there are also some participants whose parents used to speak Chinese fluently, but since they 
rarely use it, their Chinese became rusty, and there are those whose parents speak Chinese fluently, but for some reasons, they use Indonesian when they talk to their Children.

Tanti: In my family, Mandarin is not used. ... The environment is not supportive for speaking Mandarin. My mother can speak [Mandarin], but she uses Indonesian when she talks to me.

According to Tanti, her parents spoke Chinese fluently. They were able to maintain their Chinese fluency because they used the language to communicate with their relatives in China and Malaysia. However, they did not use Chinese to communicate with their children. Perhaps, it was because of the fear of the repercussion of speaking Chinese in Indonesia during the New Order period.

Alice: When I was a kid, my parents talked to me in Indonesian mixed with Mandarin. My parents' Mandarin proficiency is poor.

In Alice's mind, her parents' Chinese proficiency was rusty because they rarely used the language. With the exception of some basic Chinese words, such as kinship terms and kitchen language, her parents talked to her in Indonesian.

Despite the varieties in their family's Chinese proficiency, all participants reported that they wanted to learn Chinese. Some said that originally, their parents encouraged them to learn it, especially when there was a changing policy regarding Chinese culture after the Reform in 1998. Those coming from families where Chinese was still spoken said that the parents were anxious at the sociopolitical atmosphere that hindered the children from learning Chinese. Because of that, they never or rarely spoke Chinese to their Children. This resulted in the children's loss of the heritage language. However, the new atmosphere changed their mindset. Now, they wanted their children to speak Chinese. Participants coming from families that had limited or no encounter with Chinese also shared similar experience. Because of their parents' eagerness, they learnt Chinese. After some moments of up and down in their learning process, all of them decided to continue their Chinese courses out of their will. Tanti, for example, started learning Chinese when she was a pupil in elementary school. She stopped learning it when she was in Elementary 6, then continued her Chinese lesson in Junior High 1. She learnt Chinese on and off. She said laughingly, "Lazy." However, she started learning Chinese more seriously after she graduated from college because she thought that the ability to speak Chinese would enable her to communicate well with her business partners. Other participants shared their experiences.
Maudy: I learnt Mandarin for the first time when I was in kindergarten. My father wanted his children to speak Mandarin like him. When I entered Senior High School, I stopped learning Mandarin. However, after finishing my high school, I chose Chinese as my major. ... I decided to learn Mandarin so that I can be quite close with people in my parents' circle, most of whom are Taiwanese.

Gia: I started learning Mandarin when I was in Elementary 2 .... Once I accompanied my father [who does not speak Chinese at all] who hosted a guest from China. ... I talked to the guest in my broken Mandarin. [The encounter with the guest from China] made me aware of my potentials, the ability to speak Mandarin. ... Up till now, I am interested in studying Mandarin, [and that is why] I decided to study in Chinese department.

Some participants said that they learnt Chinese without any parental encouragement. Although he was born and grew up in a Chinese-speaking family, Sam said that his father did not encourage him to learn Chinese.

Sam: I started to learn Mandarin in Junior High 2. I went to a Chinese language center to learn Chinese. ... [It is] my own initiative. My grandparents came from China, and my father graduated from a Chinese High School. His Chinese was very good, but he did not encourage me to learn it. Instead, he asked me to learn English. ... [I wanted to learn Chinese because] I want to be able to speak Chinese with my family.

Another participant, Brian, told us that when he was in Junior High, he wanted to learn Chinese because he was interested in Chinese calligraphy. However, he emphasized that at that time his primary reason was that he wanted to understand what his parents and grandparents talked about when they spoke Chinese.

The participants' experiences showed that they wanted to learn Chinese because of their own initiatives, although they admitted that at first it was their parents who encouraged or asked them to learn it. They said that they learnt Chinese because they wanted to have a meaningful participation in the Chinese speech community. Their intention of learning Chinese reflected the idea of Bakhtin (1991) that language has a social aspect. Unlike the structuralist perspective which views language learning as the internalization of rules and structures of the target language (Hummel, 2014, p. 61), Bakhtin sees that in learning a language, learners try to use the target 
language in its speech community in order to have a meaningful participation. Thus, motivation plays an important role in the language learning process. In the case of our participants, motivational orientation is the second theme we found.

\section{Motivational Orientations}

Studies on language learning shows the importance of motivation. Gardner's socio-economic model classifies learners' motivation into two orientations, integrative and instrumental motivation (Gardner, 2001, p. 4). Our findings on the participants' motivational orientations are consistent with the Gardner's model and the results of previous studies on CHL learners, among others, Yang (2003), Lu and Li (2008), Wen (2011), and Zhang (2015), which mention that integrative and instrumental motivational orientations are significant motivators in CHL learners. Nevertheless, those findings do not capture the cultural, social, and political nuances that affect the motivational orientations of $\mathrm{CHL}$ learners in Indonesia.

Integrative motivation was found especially among the generation of Chinese Indonesians who received Chinese education before it was banned.

Melly (a late 60s vice principal of a Chinese language center): Because a person must know the language first, so that the culture can be passed down. To know the language first, but of course our vision and mission are the culture.... It is our root. If we don't have it, we will be like floating. We want this root to be passed down to younger generations, not to be cut in our generation.

Yuni (an early 70s principal of a Chinese language center): This is what we worry about. It [Chinese cultural root] is definitely faded away. ... It is important for them to understand [their cultural root].

It was understandable that people like Melly and Yuni believed that a Chinese should command Chinese. In their perspective, $\mathrm{CHL}$ learners' primary motivation is integrative. However, there were younger participants who considered that Chinese language was an identity marker of being Chinese. They shared Melly's and Yuni's opinion.

Maudy: Because I am Chinese, I should be able to speak Chinese. That is the stronger drive, besides big potential career prospect. ... It is one of identity markers.

David: Yes, because we are Chinese, probably, so we must be able to speak Chinese. ... Ideally should be able ... because of being Chinese descents.
Tanti also shared the same idea. Her experience in Malaysia where her cousin questioned her Chinese identity because her inability to speak Chinese shocked her, especially when she saw her relatives' maid spoke Chinese. She decided to learn Chinese in order to have good communication with her relatives.

Some previous studies on CHL learners' integrative motivation showed the learners' enthusiasm and personal interest in their heritage. Wen wrote that they "showed appreciation of their socio-cultural environment from which they derived feelings of pride and belonging" (Wen, 2011, p. 347). However, the sociopolitical environment of Indonesian CHL learners were unable to generate such feelings due to the lack of affiliation with China, their ancestral country, as a result of the New Order's policy. It was very difficult for the younger generation of Chinese Indonesians to develop a sense of belonging to their cultural root. They claimed they were Chinese just because of their ethnic origin. However, their Chineseness was different from that of the older generation who received Chinese education. In Yuni's words, it is hard to educate them about their cultural heritage. There is a gap between the Chinese-educated Chinese like her and those who were born and grew up during the New Order era.

Yuni: Just like my children, they are different [from us]. Different. ... Gap. There is a gap.

Melly: [Younger generations] have (different) views. ... No sense of belonging."

Despite their integrative motivation, our participants also attributed their motivation more to the economic values of Chinese, as some participants said.

Maudy, who has a Chinese-speaking family background, had an integrative motivation, but she emphasized on the career-related reason why she learnt Chinese.

... My plan is to work in a field related to Mandarin. ... I think business opportunity there [Taiwan] is quite big."

Tanti, who has the same family background, said that apart from her intention to speak Chinese to her relatives, she learnt Chinese because of her job.

... I mean if you want to import goods from China it will be easier if you speak Chinese."

Participants like Maudy, Tanti, and some others that we interviewed had the integrative motivation, but the integration is not an important factor because they emphasized more on the potential benefits of the mastery of Chinese. Norton's notion of investment in language learning could explain this situation. In the context of our research, participants believed that by 
learning Chinese "they will acquire a wider range of symbolic and material resources" (Norton \& Toohey, 2011, p. 420). Seen from this perspective, they learnt Chinese because of the instrumental motivation. In fact, most participants cited the instrumentality as their motivation.

Fifi: Personally, I think that Chinese proficiency help us find a job. Many job vacancies demand Chinese-speaking people.

Theresa: Recently, many Chinese from China come to Indonesia [for business and tourism purposes]. Human resources that understand Mandarin are very limited. Thus, if we speak Mandarin, we are one step ahead.

Enny: There are a lot of benefits [of learning Chinese]. That would be wonderful if we speak English and Chinese. If we write in our CV that we speak Chinese fluently, it will give us a better chance to get a job.

Santi: The benefit [of speaking Mandarin] is in business world. In the job market.

David (agreeing with Santi): It [Chinese] gives us advantages in our profession.

Our participants cited the instrumental motivation, like job prospects and the usefulness of the language, as the primary reason why they learnt Chinese. However, there were participants whose motivational orientation was integrative, such as learning Chinese for personal identity and family communication, but they still emphasized on the economic values of Chinese. Thus, the instrumental motivation played an important role in driving the CHL learners learn Chinese. Most participants, if not all, thought that by learning Chinese, they would have a better future in terms of career prospects. Yuni and Melly who thought that it was hard to return the younger generation of Chinese Indonesians to their cultural root also believed that the booming of Chinese language centers was propelled by the perceived economic benefits of speaking Chinese.

Yuni: They [reasons of learning Chinese] are obviously related to the economy. It would be impossible if there is no connection with the economy. Easier to find jobs, to get a higher salary.

Melly: ... with the rise of China now, it [Chinese language] is also important in the job market. ... Individuals who speak Chinese would have a better prospect in their career. As we know, nowadays there are many foreign companies who need people fluent in Chinese.

The motivational orientation that prioritizes the economic values of Chinese resonates with Wen's findings on the instrumentality of CHL learning, namely, Chinese proficiency is useful for future opportunities. This is the case in CHL learning in Indonesia, which is dominated by instrumental motivation. In a setting like Indonesia, "where Chinese culture and native speakers are not directly accessible, integrative orientation becomes a minor motivation and might be integrated into more dynamic motivational dimensions such as instrumentality" (Wen, 2011, p. 349). This instrumental motivation was also triggered by how participants perceive China's rise.

\section{Perception on the Rise of China}

China's widely reported rapid economic growth in recent years creates an image of the superpower China among our participants. The belief that China had a great influence on the global economy impressed them.

Dina: If news is about [global] economy, it may be about China, because what China does will definitely go to all over the world.

Tanti: China is more of the economic trendsetter.

The participants, exemplified by Dina and Tanti, believed that China had the power to influence the world affairs because it was the economic engine of the world. China is the "trendsetter" of the world economy. Mega (39-year-old woman) used the idea of Chinese power to motivate her daughter to learn Chinese. She did not speak Chinese, but she wanted her daughter to speak Chinese because it could give a better future. In her opinion, Chinese was "the language of people who will rule the world." This belief, that China had a great influence on the global economy, triggered the participants' interest in learning Chinese.

In the eyes of Indonesians, regardless of their ethnic group, China is an important country (Herlijanto, 2017, p. 4). Indonesian public admires China and recognizes it as an economic superpower. This admiration and recognition are translated into the desire to learn and know more about Chinese language and culture, which they see as the key to a better prospect in the future. This desire triggers their effort in learning Chinese. They learn Chinese not because it is the language of their ancestors, but because

Mega: it is more to the functionality.

Indah: it is important. ... And if I looked at job vacancy in some newspapers, people who spoke Chinese were preferred.

Enny: it gives a lot of benefits. I major in International Business Management, ... [being proficient in Chinese] is useful. 
What the participants said showed that positive impression on China as the world economic powerhouse became a motivating factor for Indonesian CHL learners. Having such a motivation and social context, the participants viewed Chinese as a tool that could give them economic value. The economic value of Chinese was manifested through its function as a means of communication that allowed them to understand and to get connected to the world economic powerhouse. Seen in this perspective, the mastery of Chinese gave them a cultural capital.

Our findings revealed that Gardner's integrative and instrumental orientations were found in the participants' motivations. However, the social milieu of the CHL learners affected and often blurred the distinctions of the two orientations. The push from their family members, believing that Chinese language is an important marker of Chinese identity, often affected their attitude towards the language.

Fifi (who went to Taiwan for a student exchange program): I was ashamed to be a Chinese who did not speak Chinese. When I was in Taiwan, I did not dare to admit that I was Chinese.

Maudy: In my opinion, a Chinese should be able to speak Chinese. One's ability to speak Chinese is one's identity marker.

Yet, they admitted that individuals' social environment influenced their ability to speak Chinese.

Gia: I believe that a Chinese should be able to speak Chinese. However, because of individuals' different conditions, there is a possibility that a Chinese can't speak Chinese.

That was why many Indonesian CHL learners, most of whom were born and grew up during the New Order era, started to learn their heritage language when the ban on Chinese language and culture was lifted. At first, it seemed that they learnt Chinese because of integrative motivation. However, "the decision to continue their Chinese is closely related to the perceived usefulness of the language career-wise, and the perceived importance of the language in today's global economy" (Wen, 2011, p. 349). Their integrative motivation was imbued with the instrumentality of Chinese. In fact, the findings in our study pointed out that the instrumental motivation was more prominent. Participants who did not make any connections between the use of Chinese language and the perceived sense of Chinese identity were much more than those who believed that there was a connection between the two.

The participants' positive view of China as the world economic powerhouse brought about the discourse of the importance of Chinese. This view triggered their instrumental motivation to learn it. They thought that Chinese could be a means of achieving their aspirations, such as getting a good job, or having a prospective career. It was this instrumentality that led them to make an investment in CHL learning. They believed that they could obtain symbolic and material resources in return for their linguistic investment. They considered that their Chinese proficiency was a "cultural capital" which could be used in the future labor market (Bourdieu, 1986). This cultural capital was institutionalized when Chinese was formalized as a part of Indonesian national curriculum. Bourdieu called institutionalized capital as "a certificate of cultural competence which confers on its holder a conventional, constant, legally guaranteed value with respect to culture" (Bourdieu, 1986, p. 248). This institutionalized cultural capital gave Indonesian CHL learners a recognition that their efforts to learn Chinese had a value, albeit a symbolic one.

\section{CONCLUSION}

This study aims at examining the intersection between Chinese Indonesians' motivation in their learning their heritage language and the rise of China as one of the global powers, through the lens of the Chinese Indonesians living in Surabaya. The findings reveal the three themes related to the participants' efforts in learning Chinese, namely, family background, motivational orientations, and perception on the rise of China. Despite coming from various family backgrounds, the participants learn Chinese out of their own initiatives. At one end of the spectrum, those coming from families where none of their members speak Chinese use the opportunity to learn Chinese as, at first, a means of reclaiming their Chinese ethnicity. However, after some time, they realize that actually they want to learn Chinese because of the economic value of the language. At the end of the spectrum, those coming from Chinesespeaking families learn Chinese because they want to have better Chinese proficiency such that they are able to use the language to communicate with their Chinese-speaking family members. Nevertheless, they also add that another important factor that encourages them to learn Chinese is job prospect and business opportunity that the mastery of Chinese can offer. In Bakhtinian perspective, despite the varieties of their family backgrounds, the participants believe in the social usage of Chinese. In this case, they learn Chinese because they are eager to be able to participate in Chinese speech community. Their eagerness is bolstered by their motivational orientations. At first glance, as previous studies on CHL show, Gardner's integrative and instrumental motivations are found among them. Their motivational orientation in learn- 
ing Chinese is either integrative or instrumental. However, when those motivations are examined further, the instrumental motivation dominates the motivations of the participants. Even the participants who have integrative motivation admit that they continue learning the language because of their perceived use of Chinese in the global economy today. Thus, the instrumentality of Chinese is the dominant factor that motivates them to learn it. The participants' instrumental motivation is reinforced by their favorable view on China's rise as a global power. This positive view inspires them to have Chinese proficiency. For them, Chinese is more than their heritage language. To borrow Bourdieu's term, Chinese language is a cultural capital that can give them an edge when they enter the workforce.

\section{SUGGESTIONS FOR FURTHER RESEARCH}

This study has at least two limitations. First, we did not discuss individual differences among Indonesian CHL learners. Discussions on those differences may enrich our understanding on their motivational orientations. Secondly, we also did not discuss Indonesian CHL learners coming from areas such as Medan or Singkawang, where the majority of Chinese Indonesians there still practice many elements of Chinese culture and speak some Chinese dialects. Those coming from areas as such may have different reasons and motivations from their counterparts living in Surabaya, most of whom have lost their heritage language. Studies on CHL by factoring those concerns may give more insights on learners' motivational orientations and shifts.

\section{ACKNOWLEDGEMENTS}

This study was made possible by the research grant from the Directorate General of Higher Education, the Ministry of Research, Technology, and Higher Education, Indonesia (grant number: 002/SP2H/LT/ DRPM/IV/2017).

\section{REFERENCES}

Bakhtin, M. M. (1986). Speech genres and other late essays. V. W. McGee, trans. C. Emerson \& M. Holquist, (Eds.). Austin: The University of Texas Press.

Bakhtin, M. M. (1991). The dialogic imagination: Four essays. C. Emerson \& M. Holquist, trans. M. Holquist, (Ed.). Austin: The University of Texas Press.

Bourdieu, P. (1986). Forms of capital. In John G. Richardson, (Ed.), Handbook of theory and research for the sociology of education (pp. 241258). New York: Greenwood Press.
Bourdieu, P. (1991). Language and symbolic power. J. B. Thompson, et al., trans. Cambridge: Polity Press.

Chen, N. (2017, November 6). 16 ge sheng 8397 kaosheng canjia Yinni quanguo 2017 nian 10 yuefen Hanyu kaoshi shengkuang huigu [8397 Candidates from 16 provinces across the country participated in the Indonesian national Chinese language examination in October 2017]. Qiandao Ribao, p. 17.

Chen, Y. (2005). Zai yi Yinni huawen jiaoyu de xianzhuang he weilai fazhan [Revisiting current situation and future development of Chinese language education in Indonesia]. In R. L. Lin, et al. (Eds.), Di san jie Yinni huawen jiaoyu yantaohui lunwen xuanji (pp. 7-16). Jakarta: Yinni Yajiada Huawen Jiaoyu Xietiao Jigou.

Gardner, R. C. (2001). Language learning motivation: The student, the teacher, and the researcher. Texas Papers in Foreign Language Education, 6(1), 1-18.

Hall, J. K., Cheng, A., \& Carlson, M. T. (2006). Reconceptualizing multicompetence as a theory of language knowledge. Applied Linguistics, 27(2), 220-240. doi: 10.1093/applin/aml013

Heller, M. (2008). Bourdieu and 'literacy education'. In J. Albright \& A. Luke (Eds.), Pierre Bourdieu and Literacy Education. New York: Routledge.

Herlijanto, J. (2017). Public perceptions of China in Indonesia: The Indonesia national survey (ISEAS Perspective 2017 No. 89). Retrieved from ISEAS website: https://www.iseas.edu.sg/ images/pdf/ISEAS_Perspective_2017_89.pdf

Hoon, C. Y. (2007, June 1). How to be Chinese. Retrieved from http://www.insideindonesia.org/ how-to-be-chinese-2

Hoon, C. Y. (2011). Chinese identity in post-suharto Indonesia: Culture, politics and media. Portland: Sussex Academic Press.

Hummel, K. M. (2014). Introducing second language acquisition: Perspectives and practices. Malden, MA: Willey Blackwell.

Lu, X \& Li, G. (2008). Motivation and achievement in Chinese language learning: A comparative analysis. In A. W. He \& Y. Xiao, (Eds.), Chinese as a heritage language: Fostering rooted world citizenry (pp. 89-108). Honolulu: University of Hawai'i, National Foreign Language Resource Center.

Mandell, P. B. (2002). On the background and motivation of students in a beginning Spanish program. Foreign Language Annals, 35(5), 530542. doi:10.1111/j.1944-9720.2002.tb02721.x

Masgoret, A. M, \& Gardner, R. C. (2003). Attitudes, motivation, and second language learning: A meta-analysis of studies conducted by Gardner 
and associates. Language Learning, 53(1), 123163. doi:10.1111/1467-9922.00227

Norris-Holt, J. (2001). Motivation as a contributing factor in second language acquisition. The Internet TEFL Journal, 8(6), 1-4.

Norton, B., \& Toohey, K. (2011). Identity, language learning, and social change. Language Teaching, 44(4), 412-446.doi:10.1017/S0261444811000309

Shih, C. (2017). Introduction: China and Chinese migrant scholarship. In C. Shih (Ed.), Producing China in Southeast Asia (pp. 3-16). Singapore: Springer.

Sutami, H. (2007). Kekhasan pengajaran bahasa Mandarin di Indonesia. Wacana, 9(7), 222-237. doi:10.17510/wjhi.v9i2.214

Tong, C. K. (2010). Identity and ethnic relations in Southeast Asia: Racializing chineseness. New York, NY: Springer.

Wen, X. (2011). Chinese language learning motivation: A comparative study of heritage and non-heritage learners. Heritage Language Journal, 8(3), 41-66.
Wen, X. (1997). Motivation and language learning with students of Chinese. Foreign Language Annals, 30(2), 235-251. doi:10.1111/j.19449720.1997.tb02345.x

Yang, J. S. R. (2003). Motivational orientations and selected learner variables of East Asian language learners in the United States. Foreign Language Annals, 36(1), 44-56. doi:10.1111/j.1944-9720. 2003.tb01931.x

Zhang, N. (2015). Motivation of Chinese heritage language learners: From a bioecological perspective (Master's thesis). Retrieved from https://docs.lib.purdue.edu/dissertations/AAI159 $8135 /$

Zhao, K. (2016). China's rise and its discursive power strategy. Chinese Political Science Review, 1(3), 539-564. doi:10.1007/s41111-016-0027-x

Zong, S. \& Liu, W. (2007). Yinni huawen jiaoyu zhengce de lishi yanbian ji qi zouxiang yuce [Historical change and trends of Chinese language educational policy in Indonesia]. Jinan Daxue Huawen Хиеуиап Xиеbao, 3(1), 1-18. 